\title{
Thermal Analysis of Precipitation in Al-Li Alloys
}

\author{
By Ryoichi Nozato* and Genji Nakai**
}

\begin{abstract}
Aging behavior of Al-base alloys containing $0.7 \sim 2.7 \mathrm{wt} \% \mathrm{Li}$ is studied by measuring specific heat vs temperature $(S-T)$ curves during heating of the alloys which have been quenched from $540^{\circ} \mathrm{C}$ and then aged at various temperatures ranging from room temperature to $300^{\circ} \mathrm{C}$ for various times. The $S-T$ curves are interpreted by comparing the shapes of the curves of other age-hardening alloys, and an ordering alloy. It is proposed that the precipitation in $\mathrm{Al}-\mathrm{Li}$ alloys takes place in a five-stage process; solid solution $\rightarrow$ disordered G. P. zones $\rightarrow$ ordered G. P. zones $\rightarrow \delta^{\prime \prime}$ (short range ordered $\mathrm{Al}_{3} \mathrm{Li}$ ) $\rightarrow \delta^{\prime}$ (long range ordered $\left.\mathrm{Al}_{3} \mathrm{Li}\right) \rightarrow \delta(\mathrm{AlLi})$, during isothermal aging at temperatures below $\sim 90^{\circ} \mathrm{C}$, where, $\delta^{\prime \prime}$ is a fine particle assumed to be a one- or two-dimensional superlattice of $\mathrm{Al}_{3} \mathrm{Li}$ in which only the short range order is developed. The symbol $\delta^{\prime}$ is restricted to describe only the large particle of a three-dimensional superlattice of $\mathrm{Al}_{3} \mathrm{Li}$. Experimental determinations are made for the stable and metastable solid solubility curves of the $\delta$ phase and G. P. zones. A "pseudo-critical temperature" $\left(T_{c}^{\prime}\right)$ of $\delta^{\prime \prime}$ and the critical temperature $\left(T_{c}\right)$ of $\delta^{\prime}$ are obtained and plotted against the Li content of the alloys. Here, the "pseudo-critical temperature" is the temperature above which the $\delta^{\prime \prime}$ is considerably destroyed during heating of the alloys.

The $\delta^{\prime \prime}$ and $\delta^{\prime}$ phases are already present in the as-quenched state from $540^{\circ} \mathrm{C}$, in the case of alloys containing more than $1.7 \mathrm{wt} \% \mathrm{Li}$.
\end{abstract}

(Received January 31, 1977)

\section{Introduction}

Age-hardening and precipitation sequences of $\mathrm{Al}-\mathrm{Li}$ alloys have been studied by several investigators ${ }^{(1) \sim(9)}$. Silcock ${ }^{(2)}$ has shown by an $\mathrm{X}$-ray study that an $\mathrm{Al}-2.2 \mathrm{wt} \% \mathrm{Li}$ alloy aged at $350^{\circ} \mathrm{C}$ produces equilibrium phase $\delta$ (AlLi, $b c c$ NaTl-type structure) and the alloy aged at $165^{\circ} \mathrm{C}$ yields transition phase $\delta^{\prime}\left(\mathrm{Al}_{3} \mathrm{Li}\right.$, superlattice with the $\mathrm{Cu}_{3} \mathrm{Au}$-type structure). Angerman $^{(4)}$ has observed by metallography that plate-shaped particles of $\delta$ are formed by the aging of $\mathrm{Al}-2.8 \mathrm{wt} \% \mathrm{Li}$ alloy at $275^{\circ} \mathrm{C}$. Yoshi-Yama et al. ${ }^{(5)}$ have shown by thin-film electron microscopy that spherical-shaped $\delta^{\prime}$ is generated in an $\mathrm{Al}-4.5 \mathrm{wt} \% \mathrm{Li}$ alloy aged at $250^{\circ} \mathrm{C}$, and that black paths of random shape exist already in the as-quenched alloys. Tamura et $a l .{ }^{(6)}$ have made some observations on physical properties of $\delta^{\prime}$ and shown that growth of $\delta^{\prime}$ is described as Ostwald ripening. Noble et $a l .{ }^{(7)}$ have determined the temperature of the

* Department of Metallurgical Engineering, College of Engineering, University of Osaka Prefecture, Sakai 591, Japan.

** Graduate School, University of Osaka Prefecture, Sakai, Japan. Present address: Sharp Corporation, Tenri 632, Japan. $\delta^{\prime}$ solvus as 240 and $300^{\circ} \mathrm{C}$, respectively for 2 and $4 \mathrm{wt} \% \mathrm{Li}$ alloys, by thin-film electron microscopy and electrical resistivity measurements. They concluded that age-hardening in Al-Li alloys was a two-stage process: Solid solution $\rightarrow \delta^{\prime} \rightarrow \delta$. Recently, Williams et al. redefined the $\delta^{\prime}$ solvus $^{(8)}$ and showed the occurrence of discontinuous precipitation ${ }^{(9)}$. Widely differing values have been reported for the temperature of $\delta$ solvus in the literature ${ }^{(1)(10) \sim(16)}$, as shown in Fig. 1 which does not include all of the reported solvus data in order to avoid

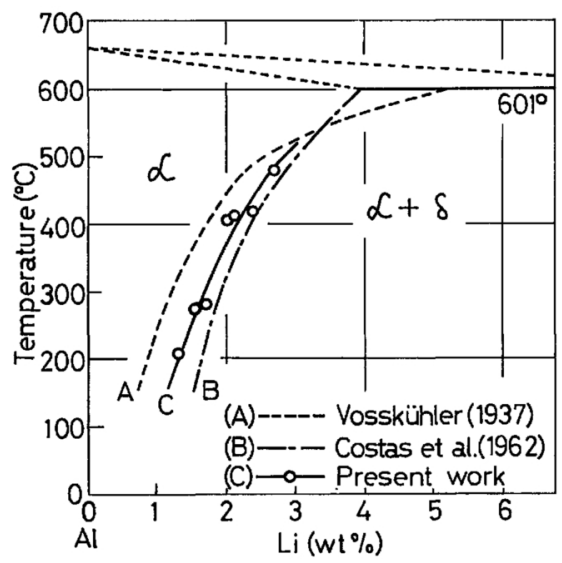

Fig. 1 Solid solubility of lithium in aluminium ( $\delta$ solvus).

1977 Vol. 18 
The ' $\mathrm{A}_{1}$ ' and ' $\mathrm{A}_{2}$ ' disappear with the occurrence of ' $D$ ' on the $S-T$ curves in the alloys aged for prolonged times at $300^{\circ} \mathrm{C}$ (Fig. $4(\mathrm{l})$ and (m)), suggesting that the solute-rich regions (1) vanish with the formation of $\delta$ at $300^{\circ} \mathrm{C}$. Thus, the solute-rich regions (1) should be clearly different in nature from the solute-rich regions (2), which assist the formations of $\delta^{\prime \prime}$ as well as $\delta^{\prime}$ and are produced as the characteristic feature of $\mathrm{Al}-\mathrm{Li}$ solid solution at such a high temperature as $540^{\circ} \mathrm{C}$. The difference in character between the solute-rich regions (1) and (2) is not obvious at the present stage of study. However, it is supposed that the solute-rich regions (1) and (2) differ from each other at least in their compositions: The former may have a $\mathrm{Li}$ concentration close to that in G.P. zones (but the composition of the G.P. zones is unknown at present). The latter may have a different $\mathrm{Li}$ concentration close to the composition of $\mathrm{Al}_{3} \mathrm{Li}$. Now, either of the following events occurs when ' $\mathrm{D}$ ' is observed on the $S-T$ curves: The energy $[C]$ is equal to that $[P]$ when both ' $C$ ' and ' $P$ ' are observed besides the ' $D$ ' (Fig. 4(l)), or all of ' $A_{1}$ ', ' $A_{2}$ ', ' $P$ ' and ' $C$ ' disappear (Fig. 4(m)). These facts suggest that the $\delta$ phase is not produced until the preexisting $\left(\delta^{\prime \prime}+\delta^{\prime}\right)$ disappears at $300^{\circ} \mathrm{C}$, that is, the $\delta$ phase does not coexists with the preexisting $\left(\delta^{\prime \prime}+\delta^{\prime}\right)$, which means that the $\left(\delta^{\prime \prime}+\delta^{\prime}\right)$ cannot transform to $\delta$ at $300^{\circ} \mathrm{C}$. Contrary to this, the $\delta^{\prime}$ can transform to $\delta$ during aging at $200^{\circ} \mathrm{C}$ which is lower than the $T_{c}$ of $\delta^{\prime}$, as mentioned for the $1.7 \mathrm{wt} \% \mathrm{Li}$ alloy (Fig. 3(j)). Figure 4 yields also Fig. 9 which shows the energies $\left[A_{1}+A_{2}\right]$ and $[B+C-P]$ as a function of aging time at $55^{\circ} \mathrm{C} ;[B+C-P]$, at $110^{\circ} \mathrm{C}$; $[B+C]$, at $150^{\circ} \mathrm{C} ;[C]$, at $200^{\circ} \mathrm{C}$; and $[D]$, at $300^{\circ} \mathrm{C}$. The $\left[A_{1}+A_{2}\right]$ is the energy required to redissolve the (G.P.1+ G.P.2) present in the aged alloy; $[B+C-P]$ and $[B+C]$, to destroy the $\left(\delta^{\prime \prime}+\delta^{\prime}\right) ;[C]$, to destroy the $\delta^{\prime} ;[D]$, to redissolve the $\delta$. The $[B+C-O-P]$, which is the energy required to destroy the preexisting $\left(\delta^{\prime \prime}+\delta^{\prime}\right)$, is also plotted with a mark $\times$ in Fig. 9 . Only the energy $[D]$ is plotted against aging time at $300^{\circ} \mathrm{C}$.

The temperature dependence of the solid solubility $\left(c_{e}\right)$ of $\mathrm{Li}$ into $\mathrm{Al}$ was determined by the least-squares method and found to be expressed in the following equation at temperatures below $500^{\circ} \mathrm{C}$ :

$$
c_{\mathrm{e}}=(31.5 \pm 4) \exp [-(7700 \pm 418) / R T]
$$

where $c_{e}$ is in at \% Li, and $R$ the gas constant in $\mathrm{J} /(\mathrm{mol} \cdot \mathrm{K})$. Thus, the solution energy of $\delta$ into the solid $\mathrm{Al}$ is $7700 \mathrm{~J}$ per mole of the $\delta$ phase. Figure 9 shows that the $[D]$ increases with increasing aging time at $300^{\circ} \mathrm{C}$ and saturates to a value $220 \pm 11 \mathrm{~J} / \mathrm{mol}(8.6 \pm 0.4 \mathrm{~J} / \mathrm{g})$, which is considered to be the solution energy $(\Delta Q)$ of $\delta$ into the matrix per mole of $2.0 \mathrm{wt} \%$ $(7.3 \mathrm{at} \%$ ) Li alloy being in an equilibrium state at $300^{\circ} \mathrm{C}$. The value of $\Delta Q$ is evaluated approximately, using the $\delta$ solvus: A value (6.1) is taken as the $c_{e}$ at $300^{\circ} \mathrm{C}$ from eq. (1), so that the fraction $(f)$ of the $\delta$ phase in the present alloy is given by $(7.3-6.1) /(50-6.1)$ for the equilibrium state at $300^{\circ} \mathrm{C}$. Thus, $\Delta Q=7700 \cdot f=209 \mathrm{~J} / \mathrm{mol}$, which agrees fairly well with the observed value. The $[C]$ in Fig. 9 is the energy required to disorder the $\delta^{\prime}$ (i.e., configurational energy of $\left.\delta^{\prime}\right)$ per gram of $2.0 \mathrm{wt} \% \mathrm{Li}$ alloy. The $[C]$ increases with aging time at $200^{\circ} \mathrm{C}$ and saturates to a value $255 \pm 11 \mathrm{~J} / \mathrm{mol}(10.0 \pm 0.4 \mathrm{~J} / \mathrm{g})$. The increase in $[C]$ is attributed to the increase in both the precipitation fraction and the LRO parameter of $\delta^{\prime}$. The saturation of $[C]$ suggests that the $\mathrm{Li}$ concentration in the matrix attains its equilibrium value $\left(c_{e}\right)$ at $200^{\circ} \mathrm{C}$ and has established a metastable equilibrium between the matrix and the fully ordered $\delta^{\prime}(25 \mathrm{at} \% \mathrm{Li})$. Therefore, the value $255 \pm 11 \mathrm{~J} / \mathrm{mol}$ is considered to be the configurational energy $\left(\Delta Q^{\prime}\right)$ of $\delta^{\prime}$ per mole of $2.0 \mathrm{wt} \% \mathrm{Li}$ alloy being in a metastable equilibrium at $200^{\circ} \mathrm{C}$. The theoretical configurational energy $(\Delta E)$ is given by $\Delta E=(R / 2.19) T_{c} \mathrm{~J}$ per mole of the $\mathrm{A}_{3} \mathrm{~B}$-type superlattice ${ }^{(25)}$. From the $T_{c}$-value $\left(245^{\circ} \mathrm{C}\right)$ for the $2.0 \mathrm{wt} \% \mathrm{Li}$ alloy, the $\Delta E$ is found to be $1960 \mathrm{~J}$ per mole of the $\delta^{\prime}$ phase. Since a value (4.5) is taken as the $c_{e}$ at $200^{\circ} \mathrm{C}$ from eq. (1), the fraction $\left(f^{\prime}\right)$ of the $\delta^{\prime}$ phase in the alloy is given by $(7.3-4.5) /(25-4.5)$ for the metastable equilibrium state at $200^{\circ} \mathrm{C}$. Thus, $\Delta Q^{\prime}=1960$. $f^{\prime}=268 \mathrm{~J}$ per mole of this alloy, which is in good agreement with the observed value, supporting the present interpretation that the reaction ' $C$ ' is due to the disordering of $\delta^{\prime}$.

In conclusion, the present results propose 
that the precipitation in $\mathrm{Al}-\mathrm{Li}$ alloys is a fivestage process for the aging at temperatures below about $90^{\circ} \mathrm{C}$ : Solid solution $\rightarrow$ G.P. $1 \rightarrow$ G.P. $2 \rightarrow \delta^{\prime \prime} \rightarrow \delta^{\prime} \rightarrow \delta$. The G.P. 2 formation should yield a small region of ordered $f c c$ structure in the matrix. The $\delta^{\prime}$ is also the ordered $f c c$ structure possessing a lattice parameter $(a=$ $4.038 \AA)^{(2)}$ analogous to that of the matrix. The resemblance in their structures and the preexistences of $\delta^{\prime \prime}$ and $\delta^{\prime}$ in the as-quenched alloys of high Li content may be a reason why the formation of G.P. zones could not be ever detected by the previous X-ray and electron diffraction studies. Suitable experimental work is desirable to ascertain the formation of G.P. zones and $\delta^{\prime \prime}$, before a definite conclusion on precipitation sequences can be given. Further experiments are in progress to detect the G.P. zones and $\delta^{\prime \prime}$.

\section{Conclusions}

(1) Five types of heat-absorption and three types of heat-evolution are observed on the $S$ - $T$ curves of the quenched and aged $\mathrm{Al}-\mathrm{Li}$ alloys. These reactions can be attributed to redissolutions of G.P.1, G.P. 2 and $\delta$, to disorderings of $\delta^{\prime \prime}$ (short range ordered $\mathrm{Al}_{3} \mathrm{Li}$ of one- or twodimensional morphology) and $\delta^{\prime}$ (long range ordered $\mathrm{Al}_{3} \mathrm{Li}$ of three-dimensional morphology), and to formations of $\delta^{\prime \prime}, \delta^{\prime}$ and $\delta$. Here, the $\delta^{\prime \prime}$ is a fine particle of $\mathrm{Al}_{3} \mathrm{Li}$ superlattice in which only the SRO parameter has a physical meaning.

(2) The precipitation in the $\mathrm{Al}-\mathrm{Li}$ alloys is a five-stage process: Solid solution $\rightarrow$ G.P. $1 \rightarrow$ G.P. $2 \rightarrow \delta^{\prime \prime} \rightarrow \delta^{\prime} \rightarrow \delta$, for the aging temperatures below about $90^{\circ} \mathrm{C}$.

(3) In the state as-quenched from $540^{\circ} \mathrm{C}$, the $\delta^{\prime \prime}$ and $\delta^{\prime}$ phases are already present and their amount increases with increasing $\mathrm{Li}$ content in the alloys containing more than $1.7 \mathrm{wt} \% \mathrm{Li}$.

(4) The stable and metastable solid solubility curves of the $\delta$ phase and the G.P. zones were determined.

(5) A pseudo-critical temperature $\left(T_{c}^{\prime}\right)$ of $\delta^{\prime \prime}$ and the critical temperature $\left(T_{c}\right)$ of $\delta^{\prime}$ were plotted against the $\mathrm{Li}$ content of the alloys. Where, the $T_{c}^{\prime}$ is a temperature above which the $\delta^{\prime \prime}$ is greatly disordered during heating of the alloys.

\section{Acknowledgments}

The authors would like to thank Prof. $\mathbf{H}$. Hagiwara for supporting the present work. They are also indebted to Showa Aluminium Co. and Mr. H. Tsubakino for determinations of $\mathrm{Li}$ contents in $1.3 \mathrm{wt} \% \mathrm{Li}$ alloy and in the other alloys, respectively.

\section{REFERENCES}

(1) H. Vosskühler: Metallwirtschaft, 16 (1937), 907.

(2) J. M. Silcock: J. Inst. Metals, 88 (1959-60), 357.

(3) W. R. D. Jones and P. P. Das: ibid., 88 (1959-60), 435.

(4) C. L. Angerman: J. Nuc. Mat., 11 (1964), 41.

(5) T. Yoshi-Yama, K. Hasebe and M. Mannami: J. Phys. Soc. Japan, 25 (1968), 908.

(6) M. Tamura, T. Mori and T. Nakamura: J. Japan Inst. Metals, 34 (1970), 919.

(7) B. Noble and G. E. Thompson: Metal Sci. J., 5 (1971), 114.

(8) D. B. Williams and J. W. Edington: ibid., 9 (1975), 529.

(9) D. B. Williams and J. W. Edington: Acta Met., 24 (1976), 323.

(10) G. Grube, L. Mohr and W. Breuning: Z. Elekctrochem., 41 (1935), 880.

(11) F. I. Shamray and P. Ya Saldau: Izvest. Akad. Nauk S.S.S.R. (Khim), (1937), 631.

(12) S. K. Nowak: Trans. AIME, 206 (1956), 553.

(13) W. R. D. Jones and P. P. Das: J. Inst. Metals, 87 (1958-59), 338.

(14) L. P. Costas and R. P. Marshall: Trans. Met. Soc. AIME, 224 (1962), 970.

(15) E. D. Levine and E. J. Rapperport: ibid., 227 (1963), 1204.

(16) Z. A. Sviderskaya and E. S. Kadaner: Izvest. Akad. Nauk S.S.S.R. (Met.), (1964), 166.

(17) K. Hirano and H. Iwasaki: Trans. JIM, 5 (1964), 162.

(18) K. Hirano: Thermal Analysis, Ed. by H. Kambe and P. D. Garn, John Wiley, New York, (1974), p. 42 .

(19) H. K. Hardy and T. J. Heal: Progress in Metal Physics, 5 (1954), 143.

(20) A. H. Cottrell: Theoretical Structural Metallurgy, Edward Arnold, London, (1962), p. 201.

(21) C. Sykes and F. W. Jones: Proc. Roy. Soc., 157 (1936), 213.

(22) H. A. Bethe: ibid., 150A (1935), 552.

(23) W. L. Bragg and E. J. Williams: Proc. Roy. Soc., 145 (1934), 699.

(24) E. V. Kozlov, V. M. Dementryev, V. N. Emelyanov, N. M. Kormin, A. S. Taylashev and D. M. Stern: Order-Disorder Transformations in Alloys, Ed. by H. Warlimont, Springer, Berlin, (1974), p. 58.

(25) M. Hirabayashi and H. Iwasaki: Kisokukosi To Kisoku-Hukisoku Hentai, Japan Inst. Metals, Sendai, (1967), p. 42. 
Table $1 \mathrm{Li}$ content of alloys (wt \%).

\begin{tabular}{lllllllllll}
\hline \hline Nominal content & 0.7 & 1.0 & 1.3 & 1.6 & 1.7 & 2.0 & 2.1 & 2.3 & 2.4 & 2.7 \\
Analyzed content & 0.72 & 1.04 & 1.29 & 1.55 & 1.68 & 1.98 & 2.09 & 2.31 & 2.40 & 2.67 \\
\hline
\end{tabular}

confusion. Most of the previous determinations of the $\delta$ solvus have been made with metallography, electrical resistivity, microhardness, and X-ray lattice parameter methods.

In the present work, the precipitation of $\mathrm{Li}$ from Al solid solution has been examined by means of measurements of the specific heat versus temperature curve, in order to obtain further information about the precipitation process and the solvus curves.

\section{Experimental Procedure}

Al-base alloys containing $0.7 \sim 2.7 \mathrm{wt} \% \mathrm{Li}$ were prepared from $99.4 \%$ lithium ${ }^{\dagger}$ and $99.99 \%$ aluminium. In addition to these alloys, an alloy containing $2.1 \mathrm{wt} \% \mathrm{Li}$ was prepared with $99.9 \%$

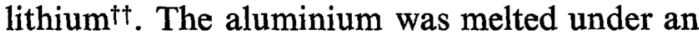
argon atmosphere in alumina crucible of high purity and lithium was added by means of a plunger made from electrode graphite of high purity and cast in an iron mold. Billets of $25 \times 25 \times 70 \mathrm{~mm}$ were annealed at $560^{\circ} \mathrm{C}$ for $72 \mathrm{~h}$ under an argon stream for homogeneization. The Li content of the billets was determined by a flame photometry method for a $1.3 \mathrm{wt} \% \mathrm{Li}$ alloy and by an atomic absorption spectrophotometry technique for the other alloys. Table 1 shows the nominal and determined $\mathrm{Li}$ contents in the alloys.

Alloy specimens of disc shape, $30 \mathrm{~mm}$ in diameter and $3 \mathrm{~mm}$ in thickness, were prepared from these billets for the specific heat measurement. Before aging, the specimen was solutionannealed at $540^{\circ} \mathrm{C}$ for $1 \mathrm{~h}$ under an argon stream and then quenched into iced water. Aging treatment was subsequently carried out at room temperature in air; at 55, 110, 150 and $200^{\circ} \mathrm{C}$, in silicon oil; and at $300^{\circ} \mathrm{C}$, in a molten salt. After the aging treatment, the specimen was quenched into iced water and then mounted

$\dagger$ Merck product, containing heavy metals ( $\mathrm{Pb}$ ) 0.005 , Fe 0.005, Ca 0.05, Na 0.5, K $0.01 \%$.

t† Alfa product, containing $\mathrm{Cl} 0.005, \mathrm{~N} 0.01, \mathrm{Fe}$ 0.002, Na 0.015, Ca 0.04, Si 0.01, others $0.001 \%$. in an adiabatic calorimeter. Measurements of specific heat vs temperature curves were made during continuous heating of the specimen over a range from room temperature to $580^{\circ} \mathrm{C}$. The rate of heating was about $2.7^{\circ} \mathrm{C} / \mathrm{min}$.

\section{Results}

Two kinds of lithium were used for the preparation of the present alloys. However, general behavior of the specific heat vs temperature curves of the alloys is not appreciably influenced by the use of two kinds of lithium.

\section{Specific heat vs temperature curves of as- quenched alloys}

Specific heat measurements have been initially made upon as-quenched alloys, and the typical results are shown in Fig. 2. About $20 \mathrm{~min}$ was unavoidably required to begin the heating of alloys for the specific heat measurement after quenching. In Fig. 2, the dotted line is the base line which is specific heat $\left(\Sigma C_{p}\right)$ vs temperature $(T)$ curve calculated on the assumption of Kopp-Neumann's rule, and the solid curve is the observed specific heat $(S)$ vs $T$ curve. The difference $\left( \pm \Delta C_{p}\right)$ between $S$ and $\Sigma C_{p}$ cannot be detected on the $S-T$ curve for the $1.0 \mathrm{wt} \% \mathrm{Li}$

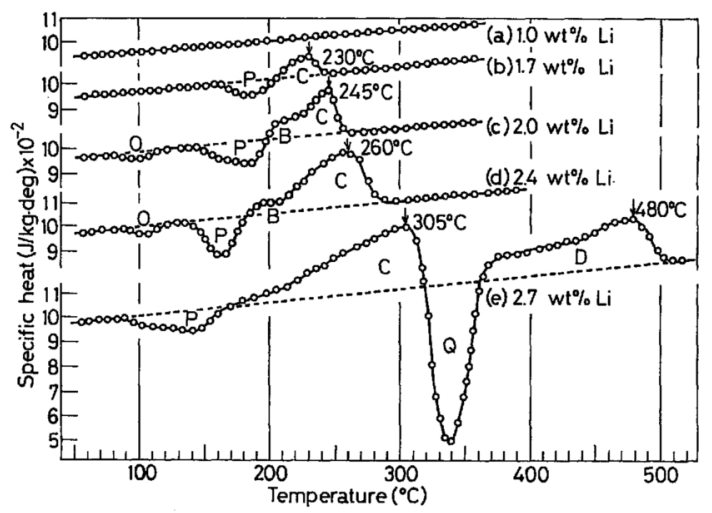

Fig. 2 Specific heat vs temperature curves of asquenched Al-base alloys containing various $\mathbf{L i}$ contents (wt \%): (a) 1.0, (b) 1.7 , (c) 2.0 , (d) 2.4 and (e) 2.7. The quenching temperature is $540^{\circ} \mathrm{C}$. 
alloy (Fig. 2(a)). The $\pm \Delta C_{p}$ is revealed in the alloys containing more than $1.7 \mathrm{wt} \% \mathrm{Li}$. The plus sign in $\pm \Delta C_{p}$ is referred to $S>\Sigma C_{p}$ and the minus sign to $S<\Sigma C_{p}$. Normally, in the case of age-hardening alloys, $-\Delta C_{p}$ is due to the evolution of heat associated with the formation of precipitate and $+\Delta C_{p}$ due to the absorption of heat accompanied by redissolution of the precipitate into the matrix solid solution.

In the $1.7 \mathrm{wt} \% \mathrm{Li}$ alloy (Fig. 2(b)), the heat evolution ' $\mathrm{P}$ ' is observed in a temperature range of about $160 \sim 205^{\circ} \mathrm{C}$ and followed by a heat absorption ' $\mathrm{C}$ ' at about $205 \sim 240^{\circ} \mathrm{C}$. In the alloys containing 2.0 and $2.4 \mathrm{wt} \% \mathrm{Li}$ (Fig. 2(c) and (d)), another heat evolution ' $O$ ' occurs in a low temperature range, about $80 \sim 110^{\circ} \mathrm{C}$. Moreover, another heat absorption ' $\mathrm{B}$ ' occurs in a temperature range lower than that of ' $C$ ', though distinction of ' $\mathrm{B}$ ' from ' $\mathrm{C}$ ' is somewhat uncertain. This distinction becomes obvious if the alloy is aged at 110 or $150^{\circ} \mathrm{C}$, as shown in the next section. The temperature range of ' $P$ ' shifts to the lower temperature side on the $S-T$ curve with increasing $\mathrm{Li}$ content, giving rise to a superposition of ' $\mathrm{P}$ ' and ' $\mathrm{O}$ ' in a $2.7 \mathrm{wt} \% \mathrm{Li}$ alloy (Fig. 2(e)). The discriminations of ' $O$ ' from ' $P$ ' and of ' $B$ ' from ' $C$ ' are quite uncertain for this alloy. Another heat evolution ' $Q$ ' occurs in a temperature range of about $320 \sim$ $360^{\circ} \mathrm{C}$ and is followed by a heat absorption ' $D$ ' in a temperature range of about 360 $510^{\circ} \mathrm{C}$.

The energy of a heat-evolution or heatabsorption reaction is determined from the area enclosed by the $S-T$ curve and the base line. The position (temperature) of the maximum of $+\Delta C_{p}$ in a heat-absorption reaction is referred to as the "temperature $\left(T_{p}\right)$ of heatabsorption peak" and shown by an arrow on the $S$ - $T$ curve.

\section{Specific heat vs temperature curves of aged alloys}

Changes in the shape of $S$ - $T$ curves of the alloys with aging time can be represented by those of two alloys containing 1.7 and $2.0 \mathrm{wt} \%$ Li. Figures 3 and 4 show the typical $S-T$ curves obtained for these alloys which have been aged isothermally at various aging temperatures for various times. The values of aging temperature and time are indicated in the figures.

(1) $S$-T curves of aged $1.7 \mathrm{wt} \% \mathrm{Li}$ alloy (Fig. 3)

A heat-absorption ' $\mathrm{A}_{1}$ ' where $T_{p}$ is observed at about $90^{\circ} \mathrm{C}$ in a temperature range of about $70 \sim 105^{\circ} \mathrm{C}$ is observed on the $S-T$ curves of the alloy aged at temperatures below about $90^{\circ} \mathrm{C}$ for a relatively short time. In Fig. 3(a), ' $A_{1}$ ' is observed for the alloy aged at room temperature for $240 \mathrm{~h}$. $A n$ ' $A_{1}$ ' is also observed in the alloy aged at $55^{\circ} \mathrm{C}$ for $4 \mathrm{~h}$. Another heat-absorption ' $\mathrm{A}_{2}$ ' having a $T_{p}$ value of about $130^{\circ} \mathrm{C}$ becomes detectable in a slightly higher temperature range (about 105 $145^{\circ} \mathrm{C}$ ) on the $S$-T curves, with increasing aging time at the temperatures below $\sim 90^{\circ} \mathrm{C}$; for example, $55^{\circ} \mathrm{C}$ (Fig. 3(b)). The energy (area) of ' $A_{1}$ ' decreases while that of ' $A_{2}$ ' increases and the ' $A_{2}$ ' apparently spreads out from about

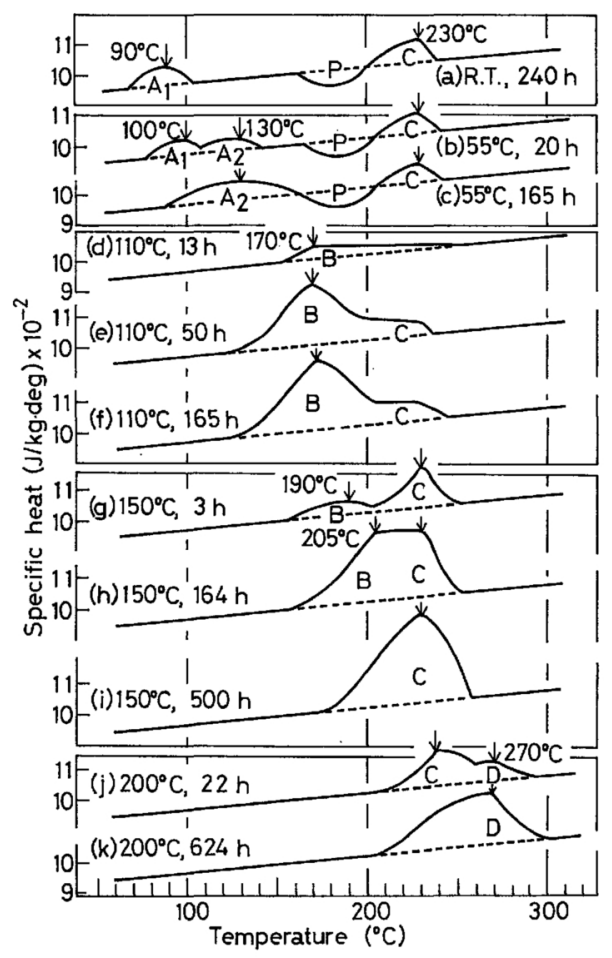

Fig. 3 Specific heat vs temperature curves of Al$1.7 \mathrm{wt} \% \mathrm{Li}$ alloy aged at various temperatures: (a) room temperature (R.T.), (b) and (c) $55^{\circ} \mathrm{C}$, (d) (f) $110^{\circ} \mathrm{C},(\mathrm{g}) \sim$ (i) $150^{\circ} \mathrm{C}$, and (j) and (k) $200^{\circ} \mathrm{C}$. The aging time is shown in the figure. 


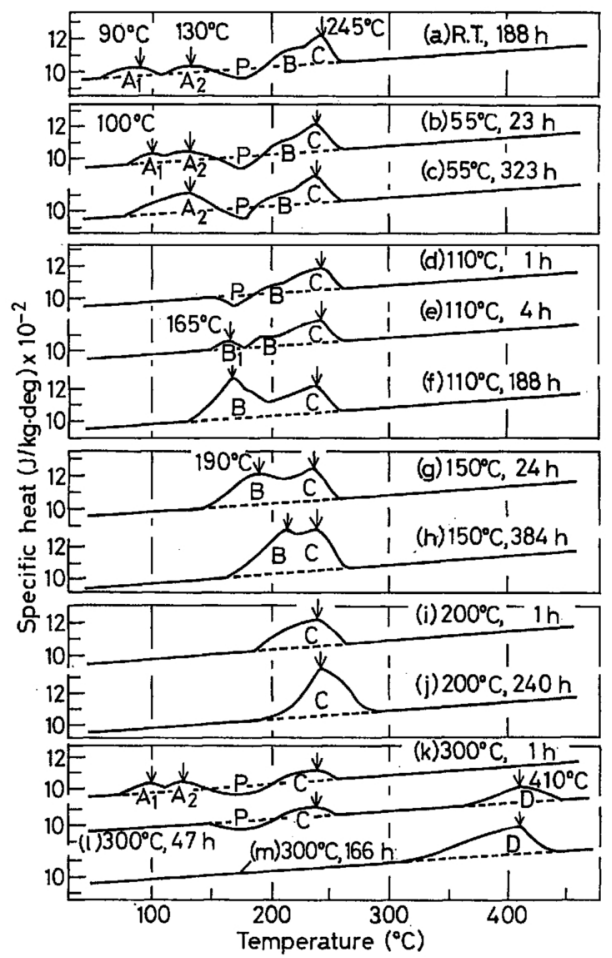

Fig. 4 Specific heat vs temperature curves of Al$2.0 \mathrm{wt} \% \mathrm{Li}$ alloy aged at various temperatures: (a) room temperature (R.T.), (b) and (c) $55^{\circ} \mathrm{C}$, (d) (f) $110^{\circ} \mathrm{C}$, (g) and (h) $150^{\circ} \mathrm{C}$, (i) and (j) $200^{\circ} \mathrm{C}$, and (k) (m) $300^{\circ} \mathrm{C}$. The aging time is shown in the figure.

90 to $160^{\circ} \mathrm{C}$ on the $S-T$ curve during prolonged aging at $55^{\circ} \mathrm{C}$, but the $T_{p}$-value of ' $\mathrm{A}_{2}$ ' remains almost constant (Fig. 3(c)). The reaction regarded as ' $\mathrm{B}$ ' is revealed in a temperature range of about $155 \sim 250^{\circ} \mathrm{C}$, in the alloys aged at $110^{\circ} \mathrm{C}$ for $13 \mathrm{~h}$ (Fig. 3(d)). The energy of ' $\mathrm{B}$ ' increases and ' $\mathrm{C}$ ' becomes somewhat obvious with aging time at $110^{\circ} \mathrm{C}$ (Fig. 3 (e) and (f). Even in the early stage of aging, both ' $B$ ' and ' $\mathrm{C}$ ' are detectable in the alloys aged at $150^{\circ} \mathrm{C}$ (Fig. 3(g)). The energies of ' $B$ ' and ' $C$ ' and the $T_{p}$-value of ' $\mathrm{B}$ ' increase with aging time at $150^{\circ} \mathrm{C}$, in such a way that ' $\mathrm{B}$ ' approaches the ' $\mathrm{C}$ ' and then disappears (Fig. 3 (h) and (i)). Both ' $C$ ' and ' $D$ ' are observed in the alloy aged at $200^{\circ} \mathrm{C}$ for $22 \mathrm{~h}$ (Fig. 3(j)). The increase in energy with aging time is more prominent in ' $D$ ' than in ' $C$ ' (Fig. 3(k)).
(2) $S$-T curves of aged $2.0 w t \%$ Li alloy (Fig. 4)

Figure 4 (a) $\sim$ (c) show similar aging behaviors of ' $A_{1}$ ' and ' $A_{2}$ ' to those in Fig. 3(a) (c), apart from the concurrent occurrence of ' $A_{1}$ ' and ' $A_{2}$ ' in the case of room temperature aging, Fig. 4(a). Another heat-absorption ' $\mathrm{B}_{1}$ ' is revealed in a temperature range lower than that of ' $\mathrm{B}$ ' in the alloy aged at $110^{\circ} \mathrm{C}$ for $4 \mathrm{~h}$ (Fig. 4(e)). Reactions ' $B_{1}$ ' and ' $B$ ' occurring separately in Fig. 4(e) are combined in the single heat-absorption ' $B$ ' in Fig. 4(f). The value of $T_{p}$ of 'B' is higher for $150^{\circ} \mathrm{C}$ aging than for $110^{\circ} \mathrm{C}$ again within the aging times of the present work (Fig. 4 (e) (h)). Reactions ' $A_{1}$ ', ' $A_{2}$ ', ' $P$ ' and ' $C$ ' similar to those observed in Fig. 4(a) occur again in the alloy aged at $300^{\circ} \mathrm{C}$ for $1 \mathrm{~h}$ (Fig. 4(k)). Reaction ' $\mathrm{D}$ ' becomes detectable with increasing aging time at $300^{\circ} \mathrm{C}$. When ' $D$ ' can be observed, the energy of ' $C$ ' is equal to that of 'P' (Fig. 4(1)) or all of ' $A_{1}$ ', ' $\mathrm{A}_{2}$ ', ' $\mathrm{P}$ ' and ' $\mathrm{C}$ ' disappear (Fig. 4(m)). Reaction ' $\mathrm{O}$ ' is difficult to be observed in the aged alloys.

\section{Temperature of heat-absorption peak}

The temperature $T_{p}$ of heat-absorption peak was determined for ' $D$ ' in the alloys containing more than $1.3 \mathrm{wt} \% \mathrm{Li}$ and is plotted against $\mathrm{Li}$ content of the alloys both in Fig. 1 which contains the solid solubility curves of $\mathrm{Li}$ into $\mathrm{Al}$ obtained by the previous workers ${ }^{(1)(14)}$ and in

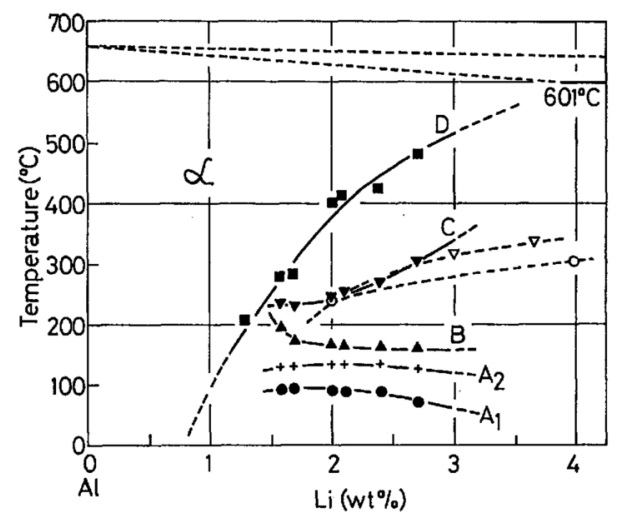

Fig. 5 Relations between "temperature of peak" of five heat-absorption reactions and $\mathrm{Li}$ content of Al-Li alloys: Curves $\mathrm{A}_{1}, \mathrm{~A}_{2}, \mathrm{~B}, \mathrm{C}$ and D. $\delta^{\prime}$ solvus: ---O--- Noble et al. (1971); --- $\nabla---$ Williams et al. (1975). 
Fig. 5 which includes the curves of $\delta^{\prime}$ solvus reported in the literature ${ }^{(7)(8)}$. The present data are shown by open circles in Fig. 1, producing a solid curve. The identical data are shown by closed squares in Fig. 5, giving rise to a curve D. The temperature $T_{p}$ of the peak was determined also for ' $A_{1}$ ', ' $A_{2}$ ', ' $B$ ' and ' $C$ ' in the alloys containing more than $1.7 \mathrm{wt} \% \mathrm{Li}$ and is plotted in Fig. 5. These plots give curves $A_{1}, A_{2}, B$ and $C$ in Fig. 5. In the previous section, it was observed that $T_{p}$ of 'B' increases up to that of ' $C$ ' with increasing aging time or temperature. The $T_{p}$-values of ' $\mathrm{B}$ ' plotted in Fig. 5 are those of the lowest value obtained in this work.

\section{Discussion}

\section{Interpretation of heat-absorptions and -evolutions}

The heat-absorption ' $\mathrm{D}$ ' can be associated with redissolution of stable phase $\delta$ into the matrix, because $T_{p}$-values of ' $D$ ' lie between the $\delta$ solvus of Vosskühler ${ }^{(1)}$ and that of Costas and Marshall ${ }^{(14)}$ in Fig. 1. Since, in the asquenched $2.7 \mathrm{wt} \% \mathrm{Li}$ alloy (Fig. 2(e)), the energy $[Q]$ of heat-evolution ' $Q$ ' is nearly equal to that [D] of heat-absorption ' $D$ ', it is evident that the total amount of the $\delta$ phase which will be dissolved into the matrix in the reaction ' $D$ ' is formed in the reaction ' $Q$ ' during heating of the alloy. Thus, ' $Q$ ' can be attributed to the precipitation of $\delta$. The temperature of the peak of ' $\mathrm{C}$ ' $\left(245^{\circ} \mathrm{C}\right)$ for $2.0 \mathrm{wt} \% \mathrm{Li}$ alloy (Fig. $2(\mathrm{c})$ ) is in fairly good agreement with the solvus temperature $\left(240^{\circ} \mathrm{C}\right)$ of $\delta^{\prime}$ reported by Noble et $a l .{ }^{(7)}$ (Fig. 5). Following these workers, therefore, the ' $\mathrm{C}$ ' is ascribed to the redissolution of $\delta^{\prime}$ into the matrix. It is conceivable that ' $\mathrm{P}$ ' is associated with the formation of $\delta^{\prime}$, because the energy $[P]$ of ' $P$ ' is nearly equal to that $[C]$ of ' $\mathrm{C}$ ' in Fig. 2(b) (1.7wt \% Li alloy).

A precise and complete interpretation cannot be put forward for the heat-absorptions ' $A_{1}$ ', ' $A_{2}$ ', ' $B_{1}$ ' and ' $B$ ' as well as the heat-evolution ' $O$ ', for we have no information about the other precipitates than the $\delta$ and $\delta^{\prime}$ at present. However, the heat-absorptions ' $\mathrm{A}_{1}$ ' and ' $\mathrm{A}_{2}$ ' revealed in Figs. 3(a) (c) and Fig. 4(a) (c) are qualitatively similar to those accompanied by the redissolution of G.P. zones reported for several Al-base alloys ${ }^{(17)(18)}$. Therefore, ' $\mathrm{A}_{1}$ ' and ' $A_{2}$ ' can be associated with the redissolution of G.P. zones. The two reactions of ' $A_{1}$ ', and ' $A_{2}$ ' are attributed to the redissolutions of two types of G.P. zones such as G.P.1 and G.P.2 designated by $\mathrm{Hardy}^{(19)}$ for the G.P. zones appearing in $\mathrm{Al}-\mathrm{Cu}$ alloy. In the present alloys, the ' $A_{1}$ ' is assigned to the G.P.1 and the ' $\mathrm{A}_{2}$ ' to the G.P.2. The decrease in the energy [ $\left.A_{1}\right]$ of ' $\mathrm{A}_{1}$ ' and the increase in that $\left[A_{2}\right]$ of ' $\mathrm{A}_{2}$ ' with aging time (Fig. 3 (b) and (c)) may be due to the development of order inside the G.P.1. The curves $A_{1}$ and $A_{2}$ in Fig. 5 are the solvus curves of G.P.1 and G.P.2, respectively.

An interpretation can be reached in terms of the superlattice phase $\left(\mathrm{Al}_{3} \mathrm{Li}\right)$ for the reactions ' $B$ ', ' $B_{1}$ ' and ' $O$ '. Development of long range order (LRO) is very slow in the superlattice alloy of $\mathrm{Cu}_{3} \mathrm{Au}$-type ${ }^{(20)}$. Thus, even when the solute-enriched regions having the composition of $\mathrm{Al}_{3} \mathrm{Li}$ are produced during the decomposition of the supersaturated solid solution, LRO may develop very slowly within these soluterich regions. That is, there is some doubt as to whether the nucleation of the fully ordered phase $\left(\delta^{\prime}\right)$ can occur or not during the decomposition of the solid solution. Therefore, it is reasonable to consider that the process of formation (or destruction) of the $\mathrm{Al}_{3} \mathrm{Li}$ phase resembles that of ordering (or disordering) in $\mathrm{Cu}_{3} \mathrm{Au}$ alloy, and hence the shape of $S-T$ curves of the present alloys should be compared with that of $\mathrm{Cu}_{3} \mathrm{Au}$ alloy ${ }^{(21)}$. The two heatevolutions of ' $\mathrm{O}$ ' and ' $\mathrm{P}$ ' occurring in the 2.0 and $2.4 \mathrm{wt} \% \mathrm{Li}$ alloys (Fig. 2 (c) and (d)) are qualitatively similar to the two reactions of heatevolution associated with short range ordering in $\mathrm{Cu}_{3} \mathrm{Au}$ alloy and with the transition of the short range order (SRO) to LRO, respectively. As described above, ' $P$ ' is concerned with the formation of $\mathrm{Al}_{3} \mathrm{Li}$. By analogy, therefore, ' $\mathrm{O}$ ' and ' $\mathrm{P}$ ' are assumed to be associated with the formation of SRO in the solute-rich regions having the composition of $\mathrm{Al}_{3} \mathrm{Li}$ and the transition of the SRO to $\mathrm{LRO}$ in the $\mathrm{Al}_{3} \mathrm{Li}$, respectively. However, 'P' cannot be attributed to the transition of the whole SRO to LRO: In the case of the $\mathrm{Cu}_{3} \mathrm{Au}$ alloy, the order develops throughout the material. On the other hand, in the case of the present alloys, the 
ordering should be confined within the soluterich regions (or precipitate particles) of small size, because the $\mathrm{Li}$ content of the present alloys is considerably less than that of $\mathrm{Al}_{3} \mathrm{Li}$ $(7.9 \mathrm{wt} \% \mathrm{Li})$. The size of these particles is determined mainly by the temperature at which the particles are produced, irrespective of their formation mechanism (spinodal decomposition or nucleation and growth). The particles in which the SRO is developed should be extremely small in size, because the ' $O$ ' and hence the formation of SRO occurs in the low temperature range $\left(80 \sim 110^{\circ} \mathrm{C}\right)$. According to electron microscope examinations ${ }^{(7)}$, the particle size of ordered $\mathrm{Al}_{3} \mathrm{Li}$ precipitates is small $(\sim 0.01 \mu \mathrm{m}$ in diameter) in the alloy aged at $100^{\circ} \mathrm{C}$. It seems that these studies ${ }^{(4) \sim(9)}$ could not well define the shape of the small particles formed at temperatures below $100^{\circ} \mathrm{C}$. Therefore, the $\mathrm{Al}_{3} \mathrm{Li}$ particles are considered to be not necessarily of spherical (three-dimensional) shape and are rather assumed to have one- or two-dimensional morphology when the size of the particles is $\sim 0.01 \mu \mathrm{m}$ or less. It is thought that the growth of order in these small particles differs from that in the bulk superlattice alloy and is strongly affected by the size and shape of the particles. Extending Bethe's conception that there is no development of LRO in a "linear chain alloy"(22), we assume that the transition of SRO to LRO is difficult to occur in the fine $\mathrm{Al}_{3} \mathrm{Li}$ particles of one- or twodimensional morphology and only the SRO parameter has a physical meaning in these particles. Thus; it follows that this transition can take place only when the particles become three-dimensional with increasing size. Now, ' $B$ ' is observed whenever the ' $O$ ' appears on the $S-T$ curves (Fig. 2 (c) and (d)). Consequently, if ' $\mathrm{O}$ ' is to be due to the formation of SRO in the one- or two-dimensional particles, ' $B$ ' should be associated with the destruction of the SRO in these particles. Even with the appearance of 'P' on the $S$ - $T$ curve, 'B' can be observed, indicating that the SRO particles which will be destroyed in ' $B$ ' is present at the temperature to finish ' $P$ '. This survival of the SRO particles after the reaction ' $P$ ' suggests that all of the SRO particles formed in ' $O$ ' do not necessarily become three-dimensional during heating of the alloys. Thus, assuming that ' $\mathrm{C}$ ' is attributed to the destruction of $\mathrm{Al}_{3} \mathrm{Li}$ of LRO $\left(\delta^{\prime}\right)$, we can draw the following conclusions concerning the reactions ' $O$ ', 'P', 'B' and ' $\mathrm{C}$ ': During heating of the alloys, the development of SRO in the particles having the composition of $\mathrm{Al}_{3} \mathrm{Li}$ occurs in ' $\mathrm{O}$ ' and the transition of SRO to LRO in the particles takes place in the ' $P$ ' leaving at least a part of SRO particles behind. Then, the remaining SRO particles and the LRO particles are destroyed in ' $B$ ' and ' $C$ ', respectively. The present assumptions enable us to sum up two curves (a) and (b) in Fig. 6 which show the dependence of extra specific heat $\left(+\Delta C_{v}\right)$ upon $T$ for two different crystals of AB-type superlattice. Curve (a) is due to disordering of SRO in the crystal of a linear chain alloy without LRO (Bethe) ${ }^{(22)}$. Curve (b) is due to disordering of LRO in the crystal of a bulk alloy without SRO (BraggWilliams) $)^{(23)}$. The addition of curve (a) to curve (b) produces curve (c) consisting of two types of heat-absorption, ' $S$ ' and ' $L$ '. The validity of application of curve (c) to the crystal of $\mathrm{Al}_{3} \mathrm{Li}, \mathrm{A}_{3} \mathrm{~B}$-type superlattice, is not proved in the present stage of study. However, it is likely that the use of the curve (c) gives a crude but plausible explanation of the behaviors of ' $B$ ' and ' $C$ ' on isothermal aging at 110 and $150^{\circ} \mathrm{C}$ (Fig. 3 (d) (i) and Fig. 4 (d) (h)): ' $\mathrm{S}$ ' and ' $L$ ' are, respectively, corresponding to ' $B$ ' and ' $C$ '. During isothermal aging, if the SRO particles increase in dimensionality with increasing size and decreases in relative amount

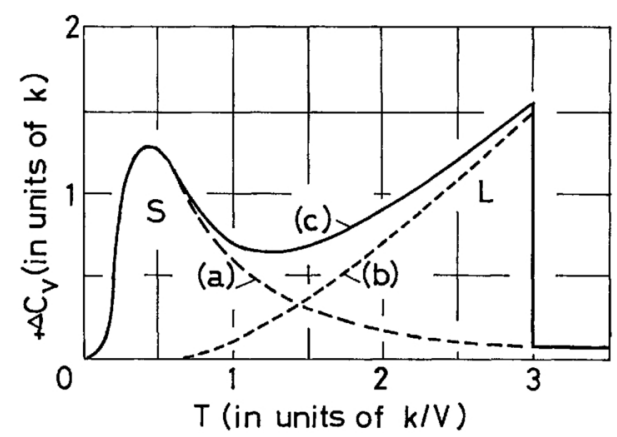

Fig. 6 Extra specific heat $\left(+\Delta C_{\mathrm{v}}\right)$ vs temperature $(T)$ curves for superlattice alloys: (a) "linear chain alloy" (Bethe); (b) bulk alloy (Bragg-Williams). Here, $k$ is Boltzmann's constant and $V$ the ordering energy. Curve (c) is (a) plus (b). 
ratio with progression of the transition of SRO to LRO through the increase in dimensionality, then 'S' ('B') approaches ' $L$ ' ('C') and disappears finally in the absence of SRO particles. In the present interpretation it is also presumed explicitly that both ' $B$ ' and ' $C$ ' are attributed to the disordering in the $\mathrm{Al}_{3} \mathrm{Li}$ particles but not to the redissolution of them into the matrix. It should be noted that the disordering in the $\mathrm{Al}_{3} \mathrm{Li}$ particles may not cause the dispersion of solute atoms into the matrix and leave solute enriched regions (solute-rich regions (1)) of disordered configurations of atoms in the matrix. Hereafter, we designate the SRO particles disordered in the ' $B$ ' as $\delta$ " and the LRO particles disordered in the ' $\mathrm{C}$ ' as $\delta$ ', restricting the symbol $\delta^{\prime}$ to describe only the $\mathrm{Al}_{3} \mathrm{Li}$ particles of relatively greater size (above the order of $0.01 \mu \mathrm{m}$ ) having the spherical morphology reported in the literature. That is, it is proposed that there exists a precipitation stage of formation of the SRO particles $\left(\delta^{\prime \prime}\right)$ which possess the composition of $\mathrm{Al}_{3} \mathrm{Li}$, but are small in size (presumably $\sim 0.01 \mu \mathrm{m}$ or less in length) and are of one- or two-dimensional morphology. In this work the $T_{p}$ of ' $\mathrm{B}$ ' is referred to as a "pseudo-critical temperature" $\left(T_{c}^{\prime}\right)$ of $\delta^{\prime \prime}$ for convenience, the $T_{p}$ of ' $\mathrm{C}$ ' being the critical temperature $T_{c}$ of $\delta^{\prime}$. Curves B and C in Fig. 5 show the dependences of $T_{c}^{\prime}$ and $T_{c}$ on the $\mathrm{Li}$ content of the alloys, respectively.

It is reasonable to consider that ' $B_{1}$ ' and ' $B$ ' observed separately in Fig. 4(e) are due to the effect that the heat-evolution ' $P$ ' occurring in Fig. 4(d) is counter-balanced by a heatabsorption ' $B$ ' resembling that observed in Fig. 3(d). An alternative to the present interpretation of the ' $B$ ' is that this is associated with the redissolution of G.P.2, i.e., ' $B$ ' is identical with ' $A_{2}$ '. The ' $B$ ', however, differs from ' $A_{2}$ ' with respect to the dependence of the $T_{p^{-}}$ value on the alloy composition and aging temperature, as seen from Fig. 5, Fig. 3 (a) (i) and Fig. 4(a) (h). Therefore, the alternative interpretation could not be adopted in the present work. The increasing sequence of $T_{p}$-value is ' $A_{1}$ ', ' $A_{2}$ ', ' $B$ ', 'C' and ' $D$ ' among the five heatabsorptions described above. This implies that the precipitation products increase their thermal stabilities in the sequence of G.P.1, G.P.2, $\delta^{\prime \prime}, \delta^{\prime}$ and $\delta$. Figure 5 contains also the five $T_{p^{-}}$ values for a $2.1 \mathrm{wt} \% \mathrm{Li}$ alloy which was prepared from $99.9 \%$ purity lithium. These $T_{p}$-values are reasonable, as compared with those for the other alloys made from $99.4 \%$ purity lithium. Thus, it is seen that the thermal stability of various precipitation products is not influenced appreciably by the impurities contained in the lithium of $99.4 \%$ purity.

\section{State of as-quenched alloys}

Only ' $\mathrm{P}$ ' and ' $\mathrm{C}$ ' reactions are observed in the $1.7 \mathrm{wt} \% \mathrm{Li}$ alloy as-quenched from $540^{\circ} \mathrm{C}$ and the energy $[P]$ is equal to the $[C]$ in Fig. $2(b)$, indicating that no precipitation product is present. The sum $[O+P]$ of two energies $[O]$ and $[P]$ of heat-evolutions ' $O$ ' and ' $P$ ' is smaller than that $[B+C]$ of heat-absorptions ' $B$ ' and ' $C$ ' in Fig. 2 (c) $\sim(\mathrm{e})$, showing that certain amounts of $\delta^{\prime \prime}$ and $\delta^{\prime}$ are present in the asquenched alloys containing 2.0, 2.4 and $2.7 \mathrm{wt} \%$ $\mathrm{Li}$. These results are in good agreement with the electron microscopic observations which show the presence of $\delta^{\prime}$ in the as-quenched alloys containing $2.1^{(8)}, 2.6^{(6)}, 4.0^{(7)}$ and $4.5^{(5)} \mathrm{wt} \% \mathrm{Li}$. The difference $([B+C-O-P])$ between $[B+C]$ and $[O+P]$ gives the amounts of $\delta^{\prime \prime}$ and $\delta^{\prime}\left(\left(\delta^{\prime \prime}+\delta^{\prime}\right)\right)$ present in the as-quenched alloys. The $[B+C-O-P]$ is plotted against the Li content of the alloys in Fig. 7. The results show that in the as-quenched state no $\left(\delta^{\prime \prime}+\delta^{\prime}\right)$ is present in the alloys containing less than $1.7 \mathrm{wt} \% \mathrm{Li}$, while $\left(\delta^{\prime \prime}+\delta^{\prime}\right)$ is present and its amount increases with increasing $\mathrm{Li}$ content in the alloys containing more than $1.7 \mathrm{wt} \% \mathrm{Li}$. Figure 7 suggests that the as-quenched state differs between the alloys containing $\mathrm{Li}$ lower and higher than $1.7 \mathrm{wt} \%$. This $\left(\delta^{\prime \prime}+\delta^{\prime}\right)$ is presumably produced either during the quenching from $540^{\circ} \mathrm{C}$ or during the unavoidable aging at room temperature for about $20 \mathrm{~min}$ prior to the specific heat measurement after the quenching. The first precipitation products formed at room temperature are deduced to be the G.P. zones, as described in the next section. Therefore, this $\left(\delta^{\prime \prime}+\delta^{\prime}\right)$ must be produced during the quenching from $540^{\circ} \mathrm{C}$. Thus, the difference in the state of as-quenched alloys arises from the difference in the structure of solid solution at the quenching temperature 


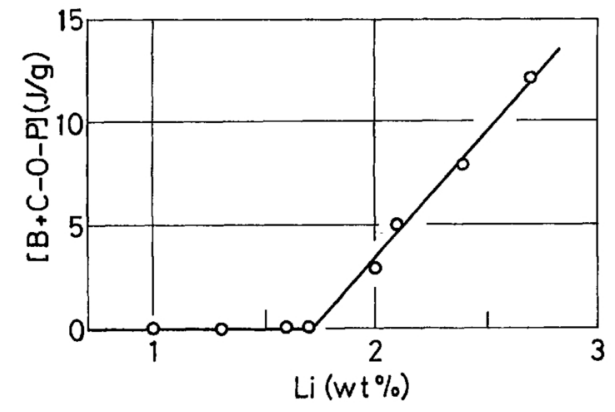

Fig. 7 Relation between Li content of the alloys and energy $[B+C-O-P]$ required to disorder the $\delta^{\prime \prime}$ and $\delta^{\prime}$ which are present in the as-quenched alloys. The quenching temperature is $540^{\circ} \mathrm{C}$.

$\left(540^{\circ} \mathrm{C}\right)$ which is identical with the solutionannealing temperature. According to Williams et al. ${ }^{(8)}$, a solution-annealing of $7 \mathrm{~min}$ at $580^{\circ} \mathrm{C}$ is sufficient to dissolve all the precipitates. Thus, the $\mathrm{Al}-\mathrm{Li}$ solid solution is almost in an equilibrium state after solution-annealing for $1 \mathrm{~h}$ at $540^{\circ} \mathrm{C}$ in the present work. On the basis of the present results, it is supposed that the distribution of solute atoms is non-random in the solid solution at the temperature $540^{\circ} \mathrm{C}$, and the following aspects can be characterized for the non-random solution: (I) Neither ' $A_{1}$ ' nor ' $A_{2}$ ' is observed in Fig. 2 (a) (e), indicating that no G.P. zones are present in the asquenched alloys. This result suggests that the solid solution at $540^{\circ} \mathrm{C}$ contains particular solute-rich regions, which facilitate the formation of $\delta^{\prime \prime}$ and $\delta^{\prime}$ while they do not assist the formation of G.P. zones. We designate these solute-rich regions formed at such high temperatures as $540^{\circ} \mathrm{C}$ as solute-rich regions (2). (II) Figure 7 shows that the solute-rich regions (2) are produded only in the alloys containing more than $1.7 \mathrm{wt} \%(6.3 \mathrm{at} \%) \mathrm{Li}$ which is nearly equal to the atomic fraction of $B$ in $A_{15} B$. Thus, it is considered that the solute-rich regions (2) are concerned with a super-superstructure $A_{15} B^{(24)}$ derived from the $A_{3} B$ superlattice of $\mathrm{Cu}_{3} \mathrm{Au}$ type under super-ordering of the unit cell of $\mathrm{Cu}_{3} \mathrm{Au}$ in the alloys of nonstoichiometric composition. That is, the solute-rich regions (2) may have a composition identical with or near that of $\mathrm{Al}_{3} \mathrm{Li}$. However, no definite conclusion can be drawn as to the nature of the solute-rich regions (2) formed at $540^{\circ} \mathrm{C}$, owing to the scarcity of currently available data on the Al- $\mathrm{Li}$ solid solution.

\section{Aging behavior}

(1) $1.7 \mathrm{wt} \% \mathrm{Li}$ alloy

Only the ' $A_{1}$ ' is observed besides the ' $C$ ' and ' $P$ ', and the energy $[C]$ is nearly equal to that $[P]$ in Fig. 3(a). Therefore, only the G.P.1 is present in the alloy aged at room temperature for $240 \mathrm{~h}$. Namely, the G.P.1 formation precedes the formation of all other precipitates at room temperature. Similar considerations for Fig. 3 (b) and (c) show that the formation of G.P. 1 and G.P. 2 precedes that of $\delta^{\prime \prime}, \delta^{\prime}$ and $\delta$ at temperatures below the solvus temperature of G.P.1 $\left(\sim 90^{\circ} \mathrm{C}\right)$, for example, $55^{\circ} \mathrm{C}$. Figure 3(d) shows that the $\delta^{\prime \prime}$ phase is the first precipitate formed at $110^{\circ} \mathrm{C}$, which is appreciably lower than the $T_{c}^{\prime}$ of $\delta^{\prime \prime}\left(\sim 170^{\circ} \mathrm{C}\right)$ and is slightly higher than the solvus temperature of G.P.1. Figure 3 (e) and (f) show the subsequent occurrence of $\delta^{\prime}$ at $110^{\circ} \mathrm{C}$. These $S-T$ curves show also an appreciable intrusion of the lower temperature part of ' $B$ ' into the temperature range of ' $\mathrm{A}_{2}$ ', suggesting that the G.P.2 can be formed also during aging at $110^{\circ} \mathrm{C}$ which is slightly lower than the solvus temperature of G.P. $2\left(\sim 130^{\circ} \mathrm{C}\right)$. However, the formation of G.P.2 at $110^{\circ} \mathrm{C}$ is difficult to be confirmed because the ' $A_{2}$ ' cannot be discriminated from the ' $B$ ' in Fig. 3 (e) and (f). Figure 3 (g) (i) indicate that both the $\delta^{\prime \prime}$ and $\delta^{\prime}$ are produced initially and then the $\delta^{\prime \prime}$ disappears by the transition of $\delta^{\prime \prime}$ to $\delta^{\prime}$ with aging time at $150^{\circ} \mathrm{C}$ which is slightly lower than the $T_{c}^{\prime}$ of $\delta^{\prime \prime}$. The transition of $\delta^{\prime \prime}$ to $\delta^{\prime}$ arises from the increase in the size and dimensionality of $\delta^{\prime \prime}$ particles with aging time. Figure $3(\mathrm{j})$ and $(\mathrm{k})$ show that no $\delta^{\prime \prime}$ is produced at $200^{\circ} \mathrm{C}$ which is higher than the $T_{c}^{\prime}$ of $\delta^{\prime \prime}$. It is known that both the $\delta^{\prime}$ and $\delta$ are formed initially and then the $\delta^{\prime}$ transforms to $\delta$ with aging time at $200^{\circ} \mathrm{C}$. Figure 3 yields also Fig. 8 which shows a total energy $\left[A_{1}+A_{2}\right]$ of reactions ' $A_{1}$ ' and ' $A_{2}$ ' as a function of aging time at $55^{\circ} \mathrm{C} ;[B+C]$ of reactions ' $\mathrm{B}$ ' and ' $\mathrm{C}$ ', at 110 and $150^{\circ} \mathrm{C}$; and $[C+D]$ of reactions ' $\mathrm{C}$ ' and ' $\mathrm{D}$ ', at $200^{\circ} \mathrm{C}$. The $\left[A_{1}+A_{2}\right]$ is the energy required to redissolve the (G.P.1+G.P.2) present in the aged alloy; $[B+C]$, to destroy the $\left(\delta^{\prime \prime}+\delta^{\prime}\right)$; and $[C+D]$, to destroy the $\delta^{\prime}$ and 


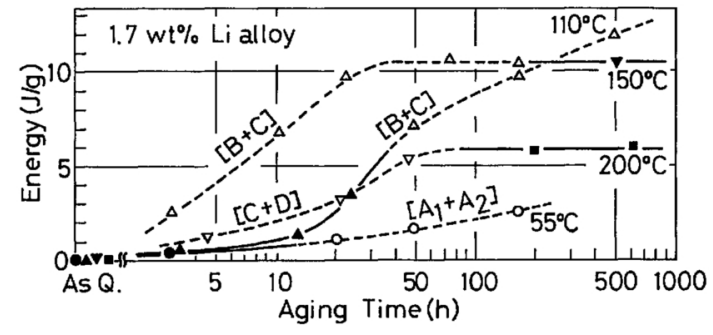

Fig. 8 Plots of energies required to redissolve or disorder G.P. zones, $\delta^{\prime \prime}, \delta^{\prime}$ and $\delta$ which are present in the aged $1.7 \mathrm{wt} \% \mathrm{Li}$ alloys against aging time at various temperatures, $55,110,150$ and $200^{\circ} \mathrm{C}$. - - G.P. 1 ; ---O--- (G.P. $1+$ G.P. 2); - $\mathbf{A}-$ $\delta^{\prime \prime} ;---\triangle--\left(\delta^{\prime \prime}+\delta^{\prime}\right) ;-\nabla-\delta^{\prime} ;---\nabla--\left(\delta^{\prime}+\delta\right)$; $-\square-\delta$.

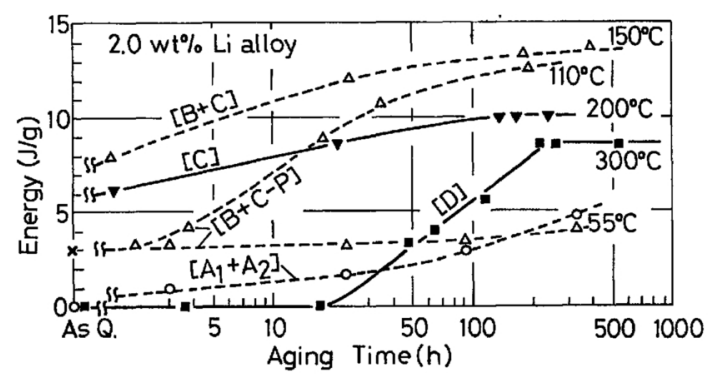

Fig. 9 Plots of energies required to redissolve or disorder G.P. zones, $\delta^{\prime \prime}, \delta^{\prime}$ and $\delta$ which are present in the aged $2.0 \mathrm{wt} \% \mathrm{Li}$ alloys against aging time at various temperatures, $55,110,150,200$ and $300^{\circ} \mathrm{C}$. $-O-$ (G.P. $1+$ G.P. 2); $\cdots-\Delta^{---}\left(\delta^{\prime \prime}+\delta^{\prime}\right)$; $-\nabla-\delta^{\prime} ;-\square-\delta$. $\times$ : preexisting $\left(\delta^{\prime \prime}+\delta^{\prime}\right)$.

redissolve the $\delta$. The solid and dotted curves in Fig. 8 and Fig. 9 in the next section imply the presence of one kind of precipitation products and of two kinds of precipitation products in the aged alloy, respectively.

\section{(2) $2.0 w t \% \mathrm{Li}$ alloy}

The general aging process of $2.0 \mathrm{wt} \% \mathrm{Li}$ alloy differs somewhat from that of $1.7 \mathrm{wt} \% \mathrm{Li}$ alloy, owing to the presence of a certain amount of $\left(\delta^{\prime \prime}+\delta^{\prime}\right)$ in the as-quenched alloys (preexisting $\left(\delta^{\prime \prime}+\delta^{\prime}\right)$ ) and its influence on the subsequent aging. It is seen from Fig. 4 (a) (c) that the G.P. zones are again the main precipitation products formed firstly during aging at temperatures below $\sim 90^{\circ} \mathrm{C}$. On room-temperature aging, however, the proceeding of G.P. 2 formation is more rapid for $2.0 \mathrm{wt} \% \mathrm{Li}$ alloy than for $1.7 \mathrm{wt} \% \mathrm{Li}$ alloy (Fig. 3(a) and
Fig. 4(a)). Formation of the G.P. zones occurs independently of the preexisting $\left(\delta^{\prime \prime}+\delta^{\prime}\right)$ in the $2.0 \mathrm{wt} \% \mathrm{Li}$ alloy, so that both the G.P. zones and the preexisting $\left(\delta^{\prime \prime}+\delta^{\prime}\right)$ are present in the alloy aged at temperatures below $\sim 90^{\circ} \mathrm{C}$. Figure 4 (d) (f) show that the $\delta^{\prime \prime}$ is newly formed during aging at $110^{\circ} \mathrm{C}$, giving rise to an increase in the amount of $\left(\delta^{\prime \prime}+\delta^{\prime}\right)$ in addition to the preexisting $\left(\delta^{\prime \prime}+\delta^{\prime}\right)$. The fact, that the $T_{p}$-value of ' $\mathrm{B}$ ' is higher for the $150^{\circ} \mathrm{C}$ aging than for the $110^{\circ} \mathrm{C}$ aging (Fig. 4 (f) and (g)), is attributed to a possibility that the size of $\delta^{\prime \prime}$ particles produced is larger and hence the dimensionality of them is probably higher for the $150^{\circ} \mathrm{C}$ aging than for the $110^{\circ} \mathrm{C}$ aging. Figure 4 (i) and (j) show that only the $\delta^{\prime}$ is newly formed and accounts for most of the precipitates in the alloy aged at $200^{\circ} \mathrm{C}$ within the aging times up to $240 \mathrm{~h}$. Figure $4(\mathrm{k})$ shows the occurrence of ' $A_{1}$ ' and ' $A_{2}$ ', which are due to the redissolution of G.P. zones, in the alloy aged at $300^{\circ} \mathrm{C}$ for a short time. It is difficult to consider that the G.P. zones are formed during the aging at $300^{\circ} \mathrm{C}$ which is considerably higher than the solvus temperature of G.P. zones $\left(\sim 130^{\circ} \mathrm{C}\right)$. These G.P. zones may be produced either on quenching from $300^{\circ} \mathrm{C}$ or on aging at room temperature for $\sim 20 \mathrm{~min}$ which are unavoidably required to begin the heating of alloy for the specific heat measurement after the quenching from $300^{\circ} \mathrm{C}$. When the alloy including the preexisting $\left(\delta^{\prime \prime}+\delta^{\prime}\right)$ is aged at $300^{\circ} \mathrm{C}$ which is also higher than the $T_{c}$ of $\delta^{\prime}\left(245^{\circ} \mathrm{C}\right)$, the disordering of the preexisting $\left(\delta^{\prime \prime}+\delta^{\prime}\right)$ may possibly precede the formation of all the precipitates. It is to be remembered that the disordering of $\delta^{\prime \prime}$ or $\delta^{\prime}$ does not cause the dispersion of solute $\mathrm{Li}$ atoms into the matrix but leaves solute enriched and disordered regions (solute-rich regions (1)) in the matrix. It is expected that the solute-rich regions (1) change their nature to act as nuclei of the $\delta$ during the aging at $300^{\circ} \mathrm{C}$ where only the $\delta$ precipitation can occur. It appears, therefore, that when the alloy is quenched from $300^{\circ} \mathrm{C}$ before the $\delta$ precipitation takes place at this temperature, the solute-rich regions (1) affecting their nature can facilitate the formation of G.P. zones on quenching or on unavoidable aging at room temperature after quenching. 